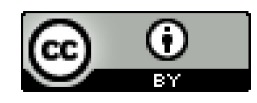

Esta obra está sob o direito de Licença Creative Commons Atribuição 4.0 Internacional.

\title{
A IMPORTÂNCIA DA HUMANIZAÇÃO NO PROCESSO DE TRABALHO NA REDE SUS HOSPITALAR
}

\author{
Suzana Peixoto de Araújo ${ }^{1}$ \\ Júlia Cláudia Tenório ${ }^{2}$ \\ Marcelo Henrique Santos ${ }^{3}$ \\ Betijane Soares de Barros ${ }^{4}$
}

\section{RESUMO:}

O presente artigo trata-se da temática "A Importância da Humanização no Processo de Trabalho na Rede SUS Hospitalar". Tendo em vista, ser um tema pertinente ao processo de trabalho dos profissionais da área de saúde, que lidam com aspectos que estão intrínsecos a necessidade da participação dos mesmos como corresponsáveis e sujeitos protagonista no processo de trabalho. Este trabalho tem por objetivo analisar a importância do processo de humanização na rede SUS hospitalar frente ao processo de trabalho. O material analisado foi obtido das bases de dados eletrônicas como Scielo, Google, cartilhas do ministério da saúde, além de materiais fornecidos pelos sites oficiais do governo. Mediante as análises dos autores e vivências dos profissionais, a humanização no âmbito ocupacional, especificamente na rede sus hospitalar, requer um atendimento acolhedor, humanizado, que não se resume ao atendimento profissional e paciente, mas requer um alinhamento dos gestores para na prática ser efetivado como um todo, um processo entre profissional/gestor/paciente.

Palavras-chave: Trabalho. Humanização. Saúde do trabalhador.

\footnotetext{
${ }^{1}$ Mestranda do Curso de Pós-Graduação em Saúde Pública, Absoulute Christian University Brasil. Email: suzanapeixoto123@hotmail.com.

2 Mestranda do Curso de Pós-Graduação em Saúde Pública, Absoulute Christian University Brasil. Email: juliatenorio2017@gmail.com.

${ }_{3}^{3}$ Mestrando do Curso de Pós-Graduação em Saúde Pública, Absoulute Christian University Brasil. Email: drmarcelo_psf_odonto@yahoo.com.br.

${ }^{4}$ Graduada em Biologia (Ciências) pela Autarquia de Ensino Superior de Arcoverde (2001), Mestrado em Ciências da Saúde pela Universidade Federal de Alagoas (2010), Doutorado em Ciências da Saúde pela Absoulute Christian University (2018).
} 


\section{INTRODUÇÃO}

A Política Nacional de Humanização nasce ao se observar às deficiências do serviço de saúde e a necessidade de humanização, como ressalta Alves, Mioto e Gerber (2006).

\section{[...] "a valorização da dimensão humana e subjetiva tornou-se a tônica da proposta, tendo como objetivo o aprimoramento das relações entre profissionais e usuários, dos profissionais entre si e melhoria da imagem dos hospitais na comunidade" [...].}

No início dos anos 2000, surge o Programa Nacional de Humanização do Atendimento Hospitalar (PNHAH), pautado na comunicação entre os usuários, profissional e gestores.

O PNHAH usa como argumento inicial os problemas identificados no relacionamento entre os profissionais de saúde e os usuários, constatado por uma pesquisa do Ministério da Saúde. DESLANDES (2004) afirma o número significativo de denúncias, feitas principalmente pela população usuária, fortalece o imaginário social e a opinião pública sobre a desqualificação dos serviços públicos de saúde.

Em 2003, a Política Nacional de Humanização - Humaniza SUS é criada pelo Ministério da Saúde, tem como balizadores as conquistas nascidas das lutas pela democratização no país, que ganham estatuto constitucional em 1988, e, também, o processo de redemocratização e resistência no âmbito da saúde por meio da Reforma Sanitária. A humanização das práticas no campo da saúde, conforme preconiza a PNH, se expressa, sobretudo, na valorização dos diferentes sujeitos envolvidos no processo de produção de saúde. O processo de humanização assim formulado refere-se não ao humano idealizado, mas à "[...] tarefa sempre inconclusa da reinvenção de nossa humanidade" (Benevides R, 2005). Nesta perspectiva, a PNH 2003, afirma:

\footnotetext{
“A humanização é a valorização dos usuários, trabalhadores e gestores no processo de produção de saúde. Valorizar os sujeitos é oportunizar uma maior autonomia, a ampliação da sua capacidade de transformar a realidade em que vivem, através da responsabilidade compartilhada, da criação de vínculos solidários, da participação coletiva nos processos de gestão e de produção de saúde”.
}

São encontrados muitos desafios pela $\mathrm{PNH}$, de superar os obstáculos no processo de humanização com ênfase no processo de trabalho dos profissionais, que são corresponsáveis e sujeitos protagonista no processo de trabalho, produzindo mudanças nos modos de gerir e cuidar. A PNH estimula a comunicação entre gestores, trabalhadores e usuários para construir processos coletivos de enfrentamento de relações de poder. Assim, 
investir em práticas de cuidado humanizado

"[...] implica reinventar a relação trabalhador de saúde-usuário/rede social, (re)inventando-se com ela (Neves CAB, 2008).

A PNH lista o processo de trabalho como um dos alvos da humanização, cuidando da democratização das relações de trabalho; fortalecer o trabalho em equipe,

\section{METODOLOGIA}

O estudo teve como embasamento a abordagem metodológica, revisão de literatura, não sistemática, cujas fontes de pesquisas são derivadas da utilização de artigos científicos. O aprimoramento e atualização da revisão foi norteado pela

\section{RESULTADOS E DISCUSSÃO}

Após selecionado o material, foram desenvolvidas as seguintes categorias temáticas: desafios na rede sus hospitalar frente a humanização no processo de trabalho e a importância do processo de humanização.

\section{Desafios na rede sus hospitalar frente a humanização no processo de trabalho}

A Humanização no âmbito ocupacional, requer a superação e muitos desafios que são encontrados frente ao processo de trabalho. É necessário que todos envolvidos no processo de trabalho promovendo a coletividade; reconhecendo o valor dos profissionais e o ambiente, organizando locais de trabalho saudáveis e acolhedores. Nesse contexto, analisar o processo de humanização é de extrema importância para a política de saúde, além de contribuir e promover os fundamentos para refletir e discutir sobre a saúde ocupacional.

temática "A Importância da Humanização no Processo de Trabalho na Rede SUS Hospitalar". No processo de pesquisa foram utilizadas bases de dados eletrônicas como Scielo, Google, cartilhas do ministério da saúde, além de materiais fornecidos pelos sites oficiais do governo.

profissional/gestor, estejam alinhados potencializando fortemente as barreiras encontradas, possibilitando avanços e conquistas. A humanização na saúde propõe um "conjunto de princípios e diretrizes que se traduzem em ações nas diversas práticas e esferas do sistema de saúde, caracterizando uma construção coletiva" (HumanizaSus, 2004).

A própria Organização Mundial da Saúde (MS, 2009), tomou a questão de "cuidar do cuidador" como tema estratégico da agenda da saúde na primeira década do novo milênio. Mas o que seria cuidar e valorizar o trabalhador? De uma forma 
suscinta pode-se apontar algumas direções.

A questão dos processos de trabalho, remuneração do trabalhador, formas de vínculo empregatício, situações de vulnerabilidade aos quais os trabalhadores são submetidos, são um dos fatores que requerem cuidados que favoreçam a produção de saúde pelo trabalhador como recurso para a dignificação de seu trabalho e ampliação de seu valor de uso.

No entanto, tendo em vista a necessidade de se democratizar as relações de poder nas organizações em saúde, uma das formas de incentivar o profissional a trabalhar com entusiasmo, é a abertura de espaços para que os profissionais possam participar na gestão dos processos de trabalho, portanto a inclusão das pessoas, de fato, nos processos de tomada de decisão nas organizações são de extrema importância para o profissional. A PNH toma a cogestão e a gestão compartilhada como uma diretriz, apostando na democratização das relações de poder como um valor e como um requisito para a ampliação da corresponsabilização dos trabalhadores (MS, 2009).

Para Souza e Mendes (2009, p. 683), a humanização envolve o refletir e o agir sobre "modos de pertencer e de circular no plano institucional, nas relações interprofissionais e com os usuários", permitindo rever a pertinência e a atualidade de nossos saberes, atitudes, de nossas formas de "ser-em-grupo" e de "fazer com o outro".

Já Pedroso e Vieira (2009) afirmam que a humanização do SUS indica mudanças nas práticas de atenção e gestão com uma aposta nos sujeitos concretos, enquanto novos homens em interação e que constroem em conjunto novas práticas de saúde em defesa da vida.

A PNH preconiza o fortalecimento do trabalho em equipe multiprofissional, fomentando a transversalidade e a grupalidade, o apoio à construção de redes cooperativas solidárias e comprometidas com a produção de saúde e de sujeitos e coletivos implicados na rede SUS, na construção de autonomia e protagonismo desses sujeitos e, consequentemente, na sua corresponsabilidade nos processos de gestão e atenção. A PNH apresenta algumas diretrizes, dispositivos e ofertas metodológicas, tais como acolhimento, clínica ampliada, equipe de referência/apoio matricial, projeto terapêutico singular, valorização dos trabalhadores da saúde, formação de redes, visita aberta e direito a acompanhante, bem como a implementação de cursos de formação, câmaras técnicas e comitês de humanização nos locais de trabalho (Brasil, 2004).

A Rede HumanizaSUS, é uma rede social que interliga pessoas interessadas ou envolvidas no processo de humanização da 
gestão e no cuidado no SUS, e a mesma foi responsável pela divulgação e explicação dos princípios e diretrizes (Brasil, 2010).

Os princípios da Política Nacional de Humanização são:

- Transversalidade, a qual requer a inserção da PNH em todas as políticas do SUS, buscando comunicação entre pessoas e grupos, tirando as relações do poder de hierarquização reconhecendo que as diferentes especialidades e práticas de saúde podem conversar com a experiência daquele que é assistido

- Indissociabilidade entre atenção e gestão busca dar informações de funcionamento da gestão dos serviços e da rede de saúde para usuários e trabalhadores para que os mesmo participem do processo de tomada de decisão nas organizações de saúde e nas ações de saúde coletiva e ao mesmo tempo conhecimento sobre os cuidados e assistências em saúde para que as responsabilidades se dividam entre a equipe de saúde e o usuário, que assume assim o papel de protagonista.

Protagonismo, corresponsabilidade e autonomia dos sujeitos e coletivos, o qual é o reconhecimento de cada pessoa como indivíduo de direito e a valorização e o incentivo do mesmo na produção de saúde
Diretrizes são as instruções que norteiam as ações, com o intuito de construir memórias exitosas e consolidadas do SUS. As da PNH são:

- Acolhimento: o acolhimento deve estar presente na relação equipes/serviços e usuários/populações para construir um elo de confiança e compromisso. O processo de escuta qualificada para a identificação dos pacientes que necessitam de atendimento prioritário e mais rápido, em razão de risco ou vulnerabilidade é umas das principais ações do acolhimento.

- Gestão Participativa e Congestão: apresenta tanto a inclusão de novos indivíduos nos processos de análise e decisão quanto à ampliação das tarefas da gestão surgidas das análises dos contextos, da política em geral e da saúde.

- Ambiência: tem como objetivo originar espaços agradáveis e saudáveis que tenha privacidade e proporcionam encontros e mudanças no processo de trabalho.

- Clínica ampliada e compartilhada: se refere a uma ferramenta teórica e prática que permite um enfrentamento da fragmentação do conhecimento e das ações de saúde por meio de uma abordagem clínica do adoecimento e do sofrimento, que considere a singularidade do sujeito e a 
complexidade

do

processo

saúde/doença.

- Valorização do trabalhador: reconhecer a experiências do trabalhador e incluí-los no processo de tomada de decisão

- Defesa dos direitos do usuário: o incentivo por meio dos serviços de saúde do conhecimento dos direitos garantidos aos usuários por lei e a garantia de que eles sejam cumpridos em todas as fases do atendimento.

\section{A importância do processo de humanização}

A proposta de humanização é um valor para a conquista de uma melhor

[...] "pode ser vista como uma forma de maximizar as potencialidades humanas, tornando produtivos os recursos humanos, em fazer as pessoas trabalharem juntas, levando para uma tarefa comum suas potencialidades e conhecimentos individuais."

Sendo assim, um processo que não se resume no atendimento técnico e mecânico do paciente, mas na compreensão e cuidado do paciente como um todo (Lunardi Filho, WD e Freire p. 1995-1996). Se faz necessário estreitar as relações interpessoais, ampliar espaços de diálogo, qualidade de atendimento à saúde do usuário e de melhores condições de trabalho para os profissionais.

Desse modo, consideramos que a humanização do ambiente hospitalar e da assistência à saúde, perpassa os fatores motivacionais externos ou somente ao usuário. O hospital humanizado é aquele que contempla, em sua estrutura física, tecnológica, humana e administrativa, a valorização e o respeito à dignidade da pessoa humana, seja ela paciente, familiar ou o próprio profissional que nele trabalha, garantindo condições para um atendimento de qualidade. Conforme afirma (Lunardi Filho WD, 1995):

acolhimento, escuta, para melhor compreensão e participação do trabalhador.

É preciso que seja estimulado e investido no trabalhador, para que o mesmo possa participar do processo de construção de proposta de humanização (Freire $\mathrm{P}$, 1996) diz que, não podemos limitar o entendimento de um atendimento humanizado como uma prática imposta, que deveria se dar de maneira vertical e fragmentada. Diferentemente, um processo de humanização do ambiente institucional pressupõe um processo participativo e dinâmico, não excludente, baseado em relações horizontais e dialógicas. 


\section{CONCLUSÃO}

Mediante as análises dos autores e vivências dos profissionais, a humanização no âmbito ocupacional, especificamente na rede sus hospitalar, requer um atendimento acolhedor, humanizado, que não se resume ao atendimento profissional e paciente, mas requer um alinhamento dos gestores para na prática ser efetivado como um todo, um processo entre profissional/gestor/paciente.

Esse trabalho possibilitou uma reflexão acerca da importância da humanização, a forma como deve ser estudada, compartilhada em equipe, ampliando espaços de diálogos entre profissionais e gestor, potencializando

\section{REFERÊNCIAS}

Benevides R, Passos E. A humanização como dimensão pública das políticas de saúde. Cienc Saude Colet. 2005; 10(3):561-71.

Brasil. Ministério da Saúde (MS). Secretaria de Atenção à Saúde. Política Nacional de Humanização da Saúde. Gestão participativa e cogestão. Brasília: Ministério da Saúde (MS); 2009. Acesso em https://www.saude.gov.br/saude-de-az/projeto-lean-nas-emergencias/693-acoese-programas/40038-humanizasus.

BRASIL. Ministério da Saúde. HumanizaSUS: a humanização como eixo norteador das práticas de atenção e gestão em todas as instâncias do SUS. Brasília, 2004. 20p. (Série B. Textos Básicos de Saúde). melhorias no cuidado. Entende-se, igualmente, a importância do constante estímulo aos profissionais já atuantes, pelas suas instituições de trabalho por meio da valorização profissional, como discussões relativas ao tema, tendo em vista o esclarecimento e sistematização dessas ações, além da promoção de debates e trocas de experiências sobre os processos que regem o cotidiano de todos envolvidos.

Sendo assim, salienta-se a necessidades de também humanizar as condições de trabalho que são postas ao profissional, para que seja estabelecido uma melhor relação para a oferta do cuidado humanizado.

DESLANDES, Suely F. Análise do discurso oficial sobre a humanização da assistência hospitalar. Ciência \& Saúde Coletiva, Rio de Janeiro, v. 9, n. 1, p.7-14, jan. 2004. Disponível em: Acesso em: 04 abr. 2019.

Freire P. Ação cultural para a liberdade. $6^{\mathrm{a}}$ ed. Rio de Janeiro: Paz e Terra; 1982. Freire P. Educação como prática da liberdade. $22^{\mathrm{a}}$ ed. Rio de janeiro: Paz e Terra; 1996.

Lunardi Filho WD. Divisão do trabalho: trabalhador especializado, trabalho (des) qualificado? Sinergia. 1995;7(2):10-80.

MIOTO, R. C. T.; NOGUEIRA, V. M. R. Desafios atuais do Sistema Único de Saúde - SUS e as exigências para os assistentes sociais. In: MOTA, A. E., et al (Orgs). Serviço Social e Saúde: formação e trabalho profissional. ABEPSS/OPAS, julho de 2006. 
Neves CAB. Humanização dos cuidados em saúde: conceitos, dilemas e práticas. Cienc Saude Colet. 2008; 13(6):1995-6.

PEDROSO, Raquel Turci; VIEIRA, Maria Edna Moura. Humanização das práticas de saúde: transversalizar em defesa da vida. Interface - Comunicação, Saúde e Educação, Botucatu, v. 13, supl. 1, p.695700, 2009.

Reis LS, Silva EF, Waterkemper R, Lorenzini E, Cecchetto FH. Humanização da percepção em saúde de uma equipe de enfermagem em unidade de terapia intensiva neonatal e pediátrica. Rev Gaúcha Enferm. 2013.

SOUZA, Luiz Augusto de Paula; MENDES, Vera Lúcia Ferreira. O conceito de humanização na Política Nacional de Humanização (PNH). Interface Comunicação, Saúde e Educação, Botucatu, v. 13, supl. 1, p. 681-688, 2009. 